\title{
Editorial
}

\section{Trabajo Social en America Latina: balance, desafíos y perspectivas}

Si revisáramos las temáticas que han convocado a distintos eventos profesionales a lo largo de América Latina en los últimos años, encontraremos que en todos ellos está presente, de una u otra manera, la referencia a la discusión de la dimensión ético-política del Trabajo Social, en una perspectiva crítica. Lo cual estaría dando cuenta de que por estos tiempos hay una inversión colectiva en el campo profesional, que está empeñada en abrir nuevos caminos, con base en el capital acumulado, y en relación con el contexto socio-político que nos toca vivir. Seguimos, pues, reflexionando acerca del Trabajo Social en relación a las condiciones sociales y a su capacidad de respuesta frente a las mismas. Al decir de Nicolás Casullo, permanecemos "con la vigilia de la negatividad, con el insomnio de teorías de la sospecha frente a los arrasadores espíritus de época". Esa vigilia de la negatividad recorre las páginas de esta edición. Como se expresa en uno de los artículos, nuestra región vive un momento histórico, con fuerte sesgo latinoamericano, que no se veía desde hace décadas. América Latina está siendo recorrida por un intento de ruptura con los tiempos inmediatamente precedentes, cuyo destino no está, ni mucho menos, asegurado a priori. Pero el intento existe, con la fuerza que le otorga el resurgir de fuerzas políticas y sociales que se expresan a través de la politización de sus necesidades. Y como no podía ser de otra manera, ello se traduce en nuestros debates, en nuestros interrogantes, en nuestras producciones.

Respecto de estas últimas, sabemos que en distintos momentos de la historia, la discursividad hegemónica del Trabajo Social sufrió algunos desbalanceos en sus posiciones, unas veces a favor de análisis más estructurales, otras a favor de los problemas específicos del campo. Pero una comprensión de los problemas macro debe ir necesariamente acompañada del análisis del campo profesional en términos estrictos. Un campo nuevamente interpelado que demanda reestructuraciones, y el renovado esfuerzo de reconsiderar la inserción del Trabajo Social en las relaciones sociales que se entablan en el actual escenario, el impacto de las transformaciones sociales actuales en el seno de la profesión, las modificaciones en las políticas sociales, las demandas actuales a la profesión, la formación profesional, la producción de conocimientos.

Encuentro como un atributo positivo en algunas de las producciones que aquí se presentan una articulación minuciosa, teóricamente fundada, entre el texto y el contexto de nuestra profesión, que coloca en la agenda de debate cuestiones sustantivas: entre ellas, la relación entre Trabajo
Social y democracia, las Políticas Sociales y su carácter contradictorio e indispensable como terreno de disputa en el campo de acceso a la riqueza social, la recuperación de categorías centrales - como la de dependencia - para la autocomprensión de la situación latinoamericana. Y asimismo, la producción de conocimientos, la formación profesional, la historia de la profesión. Todos estos temas resultan sustantivos y no accesorios, y ello por dos razones: en primer lugar, porque permiten establecer convergencias entre las modificaciones en el terreno de la lucha distributiva en el ámbito societal y estatal y el Trabajo Social, y en segundo lugar porque marcan las posibilidades y constreñimientos del despliegue y de la direccionalidad de nuestra profesión.

Y pareciera que se abren nuevas posibilidades. De hecho, el eje que articula a la presente publicación lo dice, al proponer la discusión sobre Trabajo Social en América Latina: balance, desafíos y perspectivas. Menciono como antecedente una publicación muy importante, de CELATS, que, coincidentemente, lleva el nombre de Trabajo Social en América Latina. Balance y perspectivas, y que data del año 1982, momento en que ese extraordinario movimiento profesional denominado Reconceptualización exigía ser revisado, al mismo tiempo que nuestras sociedades entraban en el cono dramático de la reestructuración neoliberal. Pareciera entonces que cuando se fijan tiempos de balance y desafíos, se hace bajo la hipótesis de que vivimos un tiempo de inflexión, que es necesario detenerse, reflexionar y lanzar propuestas. Creo que este nuevo momento desafiante permite el renacer de ciertas utopías. Una utopía que, como dice Feyerabend, no es una ensoñación cualquiera, sino una posibilidad de aquilatar en los términos más justos posibles tanto las desdichas como las oportunidades de este momento transformador. Una utopía, entonces, que se niega a la evasión a través de propuestas ensoñadoras, pero que es capaz al mismo tiempo de alcanzar ese prudente optimismo que nos ayude a establecer cuáles son las tareas para este momento, en el seno de las instituciones en que se inscribe nuestra labor, sean estas instituciones académicas, gremiales o del ejercicio profesional.

Los distintos autores que ocupan estas páginas - que abarcan a siete países y expresan perspectivas teóricas diferentes y aún divergentes - plantean problemas que resultan núcleos duros de la labor profesional, y lo hacen con bases teóricas sólidas, pero también con convicciones, 
no fundamentalistas pero sí fundadas, y con utopías, no prometeicas pero sí razonables, desde una razón que no es prescriptiva sino argumentativa, y por lo tanto capaz de instalar nuevos problemas en la agenda de los debates colectivos. Todos los temas abordados son problemáticos y controversiales, y admiten puntos de vista diversos. Las posiciones de los autores dibujan un abanico plural de tendencias, pero todos ellos nos lanzan a un abordaje más complejo del Trabajo Social inmerso en la compleja urdimbre que se desarrolla en la interfase entre Estado, Mercado y Sociedad. Y por lo tanto, arrojan luz en la discusión sobre las perspectivas y desafíos del Tabajo Social.

En relación a los desafíos y perspectivas, entiendo que sigue siendo válido - y en este número encontraremos suficientes razones - nuestro posicionamiento en pro de la extensión y exigibilidad de los derechos sociales y de su gestión democrática, que no es más que la interiorización en el campo profesional de las demandas actuales de distintos actores políticos y sociales. La exigibilidad y justiciabilidad de los derechos económicos y sociales es un proceso social, político, cultural y legal, y por lo tanto nos involucra como categoría profesional. El modo y el grado en que un Estado cumple sus obligaciones respecto de los derechos económicos y sociales debe abarcar la participación activa y organizada de la sociedad civil, y esta participación es constitutiva de ciudadanía.

Una estrategia de exigibilidad requiere una plataforma social, sostenibilidad de actores, de organizaciones, de sujetos sociales que se reconozcan como sujetos de derechos, y que por lo tanto cuenten con el capital necesario para organizarse, movilizarse y exigir su plena realización. Por tanto, una inversión importante en cualquier estrategia de exigibilidad será, sin duda, la inversión que hagamos en la recomposición del tejido social, pero también en la exploración de los núcleos potenciales de exigibilidad en las leyes vigentes, la exploración de los vacíos legales existentes, de los actos administrativos violatorios de los derechos, de los antecedentes existentes en el nuestro y en otros países, lo cual nos provee un campo inmenso de investigación.

Planteaba al comienzo que permanecemos con la vigilia de la negatividad. De eso se trata el trabajo crítico. Un trabajo crítico que no se agota, a mi criterio, en un proyecto ético-político, sino que pretende abordar un proyecto intelectual; por lo tanto, una crítica que atraviesa la teoría, la metodología, la ética y la política. Una crítica que no es romántica, en tanto que no es nostalgia por un pasado supuestamente pleno. Un trabajo crítico que nos ayude a desembarazarnos de la inmediatez, de la queja, de la imposibilidad, que ilumine "lo que resta por hacer" y nos permita reconocer los distintos momentos sociales como necesarios pero no eternos, y que por lo tanto nos impulse a estudiar la realidad advirtiendo - no sólo soñando o anhelando - sus tendencias transformadoras.
Las páginas de esta publicación nos orientan en esta dirección, y colaboran, en suma, en reafirmar el sentido de nuestro oficio, que no es otro que reducir las asimetrías a través de la construcción de justicia.

\author{
Nora Aquín \\ Secretaria Investigación y Posgrado \\ Escuela de Trabajo Social \\ Universidad Nacional de Cordoba - Argentina
}

